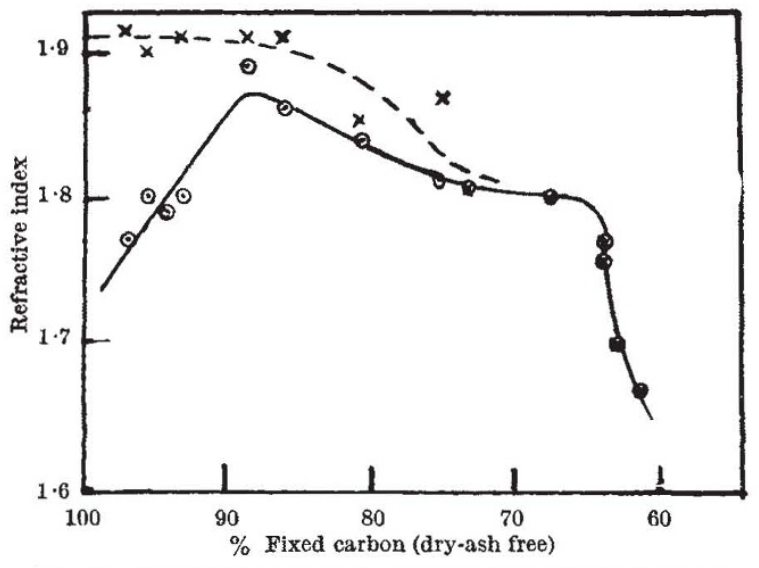

FIG. 2. REFRACTIVE INDEX IN DIRECTION PARALLEL (CIRCLES) AND PERPENDIOULAR (CROSSES) TO BEDDING PLANE RESPECTIVELY.

with 'rank' and then decreases for anthracitic coals ; (iii) the development of optical anisotropy coincides with the disappearance of coking properties.

For comparison, results for American coals are $1 \cdot 76-1 \cdot 87$ for bituminous and semi-bituminous coals ${ }^{2}$ and between 1.63 for a lignite and 1.80 for a bituminous vitrain ${ }^{3}$. Thanks are due to Dr. D. H. Bangham and Dr. C. A. Seyler for the loan of specimens.

Physies Department,

Chelsea Polytechnic,

London, S.W.3.

Dec. 17.

'Cannon and George, Nature, 150, 690 (1942).

"Fisher, Amer. Min., 19, 133 (1934).

McCabe, Fuel, 16, 309 (1937).

\section{Microscope Observations of the Crushing of Coal}

So far as I am aware, the peculiar effect described below of a disruptive pressure on small particles of coal has not hitherto been observed. The observations were made in the course of an examination of very fine coal dust from a ball mill which is claimed to grind coal to micron size.

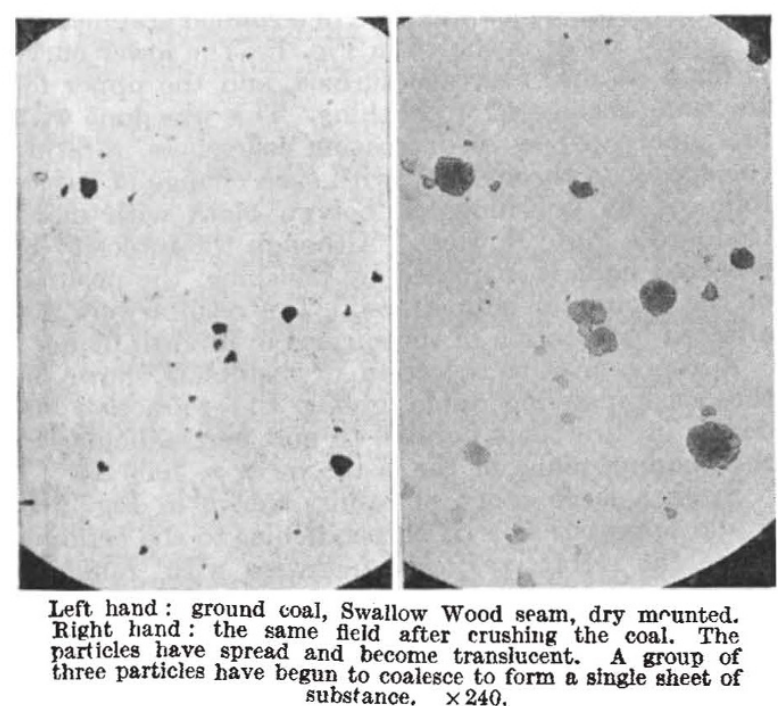

The microscope showed that the sample of dust contained particles up to thirty microns in diameter. A micro-sealpel was pressed on a cover-glass near a selected particle and the effect was watched. As the pressure was increased there came a point at which the particle collapsed into smaller particles which under continued pressure spread and coalesced into a brown patch. Under further pressure the patch spread and became correspondingly lighter in colour and, when about 0.1 micron in thickness, broke into smaller pieces, and then disintegrated into a cloud of fine particles. The accompanying illustrations show the same field of a dry mount of some coal dust of the Swallow Wood seam, a coking coal, before and after it.had been crushed on the slide. The particles have all spread and become translucent, and three of them in the centre of the field have begun tc coalesce.

The effects of crushing vary considerably according to the type of coal, but in general it seems that coal can behave as a plastic substance. Even anthracites, which hitherto have been obtained only as opaque even in the thinnest section, have become translucent under the simple manipulation described. The observations will be published in more detail elsewhere.

Safety in Mines Research Board, R. G. H. B. BoDdy. Research Laboratories,
Portobello Street,
Sheffield, 1. Dec. 9.

\section{Development of Penicillium on the Cut Surfaces of Certain Vegetables}

WHILE making certain experiments designed to test the efficacy of various fungicides we encountered an interesting phenomenon. We noted that when the cut surfaces of potato tubers were dipped momentarily in a $2 \frac{1}{2}$ per cent solution of copper sulphate, Penicillium developed copiously on these cut surfaces within five days if they were kept under moist conditions, but similar untreated surfaces were un. contaminated by this or any other fungus. Further cut surfaces of sugar-beet, turnip, Jerusalem arti choke, carrot and onion reacted similarly, althougl growth was less noticeable on earrot; here also un treated cut surfaces did not readily develop fungal growth.

As the effect was so striking the matter was explored further, and a similar reaction was found to occur when solutions or suspensions of other copper salts were used, namely, the acetate, chloride, nitrate, carbonate, chromate, formate and salicilate, also copper potassium sulphate and copper ammonium sulphate. With potato tubers, and when using copper sulphate, discoloration of the tissues preceded Penicillium development. It was noted, however, that with concentrations of copper sulphate below one per cent, Penicillium had not developed after seven days although discoloration had developed at concentrations as low as one in four hundred. As it was of interest to determine if this reaction could be produced with solutions or suspensions of other metallic salts, a number of these were tested, namely, the nitrates of barium, bismuth, calcium, cobalt, iron, lead, magnesium, mercury, nickel, potassium, silver, sodium, strontium and zine. A marked and early growth of Penicillium occurred only when the cut surfaces were treated with the cobalt salt, 